\title{
LA PUGNA HISPANO-LUSA POR EL CONTROL DE LOS MARES: DE LA EXPEDICIÓN DE CEVALLOS A LA FRUSTRADA COLONIZACIÓN DE FERNANDO POO (1776-1783)
}

\author{
Manuel Hernández González \\ (Universidad de La Laguna) \\ mvhdez@gmail.com
}

\section{RESUMEN}

Este artículo aborda el estudio de los proyectos españoles para acabar con el contrabando portugués en la colonia del Sacramento. Aprovechando la coyuntura de la Guerra de Independencia de los Estados Unidos, fue efectuada una expedición a cargo de Pedro de Cevallos con el objetivo de ocupar Santa Catarina y la colonia. La Corona decidió intercambiar la primera por las islas de Fernando Póo y Annobón en Guinea, que en realidad no eran posesiones lusas. Ello derivó en un desastroso y fracasado proyecto de colonización, que terminó con el abandono de tales establecimientos y un número elevado de pérdidas humanas durante ese intento.

PALABRAS CLAVE: Historia bélica; diplomacia hispano-lusa; guerra entre España y Portugal; colonización española en Guinea; batalla por el control del Atlántico; expedición de Cevallos contra la América portuguesa.

\section{THE HISPANIC-PORTUGUESE FIGHT FOR THE CONTROL OF THE SEA: FROM THE EXPEDITION OF CEVALLOS TO THE FRUSTRATED COLONIZATION OF FERNANDO POO (1776-1783)}

\begin{abstract}
This article addresses the study of Spanish projects to end Portuguese smuggling in the Colonia del Sacramento. Taking advantage of the conjuncture of the War of Independence of the United States, an expedition was carried out by Pedro de Cevallos with the objective of occupying Santa Catarina and the colony. The Crown decided to exchange the first for the islands of Fernando Póo and Annobón in Guinea, which in reality were not Portuguese possessions. This led to a disastrous and failed colonization project that ended with the abandonment of such settlements and a high number of human losses during that attempt.
\end{abstract}

KEY WORDS: War history; Hispanic-Portuguese Diplomacy; war between Spain and Portugal; Spanish colonization in Guinea; battle for control of the Atlantic; expedition of Cevallos against Portuguese America. 


\section{INTRODUCCIÓN}

Los pocos resultados del Tratado de límites de 1750, la actuación agresiva del marqués de Pombal sobre los dominios españoles en el escasamente poblado y defendido Río de la Plata con la ocupación del Río Grande de San Pedro y la continuidad del establecimiento de la Colonia de Sacramento derivará en la necesidad ineludible de una expedición armada contra la isla de Santa Catarina y ese último centro portuario, cabecera de una importante red de contrabando en que estaban implicados lusos y británicos. Durante los años de 1769 y 1770 los portugueses habían extendido sus correrías por las sierras de los Tapes, las jurisdicciones de Montevideo y San Carlos y las estancias de las Misiones en las márgenes del río Uruguay. Habían aumentado sus tropas con serias amenazas sobre las precarias posesiones hispanas en aquella región. La nueva colonia portuguesa de Paulistas se había erigido en los dominios del Rey de España sobre el río Gatini a 30 leguas de la villa de San Isidro Labrador de Curuguati. Las autoridades lusas al mismo tiempo habían dado apoyo a los ladrones de ganado en todo el terreno de la banda septentrional desde el Río Grande de San Pedro hasta la villa del Río Pardo, fundando más de sesenta estancias en el término de dos años. El temor a una posible guerra con Inglaterra había dilatado una expedición punitiva contra Portugal hasta que el comienzo de la insurrección de las colonias anglosajonas de América del Norte vislumbró el carácter más factible de esta incursión bélica. El objetivo de este estudio es tratar de integrar la exitosa ocupación de tales territorios con los intereses españoles en consolidar un dominio insular en el golfo de Guinea que le permite alcanzar dos de los grandes objetivos de la política colonial española: por un lado, facilitar la introducción en sus dominios americanos de esclavos negros, a través de esta base estratégica, interés que se materializará pocos años después en la liberalización de la trata a partir de 1789. Por otro su conversión de Fernando Póo y Annobón en núcleos de avituallamiento y escala de los buques de la Compañía de Filipinas impulsada por la Monarquía. Para ello era imprescindible su colonización y ello condujo al traslado de familias canarias para garantizarla, medidas que por esas mismas fechas había posibilitado José de Gálvez en la Luisiana española y la costa de los mosquitos ${ }^{1}$. Dentro de esa perspectiva política no es casual la vinculación de los nuevos territorios al recién creado Virreinato del Río de la Plata, de donde partiría precisamente la empresa, reforzada por navíos militares procedentes de Cádiz y el Santiago isleño con pobladores y provisiones.

\footnotetext{
${ }^{1}$ Véase al respecto Gilbert Din, Los canarios de Luisiana, (Las Palmas: Casa de Colón, 2010). Manuel Hernández González, "Bajo el impulso regio. La migración canaria y los batallones de Cuba y Luisiana (1776-1798)", en Del espacio cantábrico al mundo americano: perspectivas sobre migración, etnicidady retorno, coords. Óscar Álvarez Gila, Juan Bosco Amores Carredano, (Vitoria: Universidad del País Vasco, 2015) 141 169. María Luisa Martínez de Salinas Alonso, La colonización de la costa centroamericana de la Mosquitia en el siglo XVIII. Familias canarias en el proyecto poblador, (Valladolid: Universidad de Valladolid, 2015).
} 


\section{EL DEBATE DE LOS PROYECTOS BÉLICOS FRENTE A PORTUGAL EN EL GOBIERNO DE LA MONARQUÍA}

El tratado de límites de 1750, cuyo objetivo era la búsqueda de una nueva delimitación fronteriza, tuvo escasa efectividad por la continuidad del dominio luso en la Colonia del Sacramento, emplazada frente a Buenos Aires y próxima a Montevideo y la expansión de ese país en el Río Grande de San Pedro². En 1761 el de anulación hacía retornar los límites a los vigentes antes de 1750, con lo que ese significativo puerto pasó a soberanía portuguesa. Durante la guerra de los siete años el gobernador bonaerense Pedro Cevallos ${ }^{3}$ tomó ese establecimiento en 1762, pero la derrota final condujo a su devolución en la paz de París de 1763. La posición agresiva del primer ministro de José I, el marqués de Pombal, se tradujo en expediciones bélicas desde Brasil. Partía de la premisa de que la réplica española conduciría de inmediato en la intervención en la guerra de sus aliados británicos.

Ante el impacto de la participación en cualquier acción militar de los ingleses la actitud de Carlos III fue más diplomática que militar. Pero el panorama cambió con la insurrección de las colonias británicas de América del Norte. Este levantamiento emancipador era beneficioso para la Monarquía española porque concentraba todas sus fuerzas terrestres y navales en ese escenario y dificultaba la ayuda a los lusos en la región meridional. Las reformas militares y navales hispanas permitían disponer de unas fuerzas armadas que podían intervenir no solo en acciones defensivas sino de ataque, aunque el estrepitoso fracaso de la invasión de Argel actuaba como una limitación. 1775 se convertía en una coyuntura propicia para una acción militar que se tradujese en una solución definitiva de los límites territoriales en América del Sur.

Esta nueva situación condujo a un debate en el seno del gobierno sobre la política a seguir para ocupar definitivamente la Colonia del Sacramento y redefinir los límites fronterizos con Brasil. El primero en exponer su posición al respecto fue el ministro de guerra, conde de Ricla, que presentó un proyecto el 4 de octubre de 1775 que conduciría a la expedición de Cevallos del año siguiente. Sin embargo, en su

\footnotetext{
${ }^{2}$ Demetrio Ramos, El Tratado de límites de 1750 y la expedición de Iturriaga al Orinoco, (Madrid: C.S.I.C., 1946).

${ }^{3}$ Pedro Cevallos había nacido en Cádiz el 29 de junio de 1715. Era hijo de Juan Antonio Cevallos y Juana Cortes Arévalo. Su padre, originario de Santibáñez, en el actual término municipal de Cabezón de la Sal (Santander), donde nació el 17 de agosto de 1665, fue caballero de Alcántara y corregidor de Salamanca entre 1706 y 1714. A partir de ese año ejerció como subintendente de las rentas reales de Cádiz y desde el 1 de julio de 1718 como primer intendente de Canarias, tras haberse efectuado su nombramiento el 16 de marzo. Había contraído nupcias en Don Benito (Badajoz) el 22 de diciembre de 1703 con Juana Cortés Arévalo, matrimonio que había tenido la descendencia de cuatro hijos, entre los que se encontraba Pedro. Su puntillosa gestión contra el contrabando, especialmente de tabaco, junto con un conflicto con su esclavo y la mujer que pretendía libertarlo casándose con él, derivó en una rebelión popular que condujo a su muerte en Santa Cruz de Tenerife el 19 de junio de 1720. Sobre el virrey véase, Enrique M. Barba, Don Pedro de Cevallos, (Madrid: Ediciones de Cultura Hispánica, 1988, $3^{\mathrm{a}}$ ed). Sobre su padre, Manuel Hernández González, Una rebelión contra la Intendencia. El motín de Santa Cruz de Tenerife de 1720, (Tenerife: Ediciones Idea, 2007).

4 Ángel Sanz Tapia, El final del Tratado de Tordesillas: la expedición del virrey Cevallos al Río de la Plata, (Valladolid: Junta de Castilla y León, 1994).
} 
propuesta, fechada en Madrid el 22 de octubre de 1775, si bien reconocía que la proposición gubernamental se reducía a efectuar «con la mayor prontitud una expedición a las colonias portuguesas de la América», que se estimaba más ventajosa que ninguna otra, entendía que los lusos «nos insultan porque también sus fuerzas son mayores que las nuestras» suponía inmenso el gasto de la empresa, que traía consigo el acopio de veinte mil hombres y una escuadra de entidad y las fortificaciones de los puertos. Por tales razones promueve la intervención directa en los dominios continentales. Creía que para la conquista de Portugal contaría con el auxilio de las tropas galas ${ }^{5}$. En efecto, el objetivo de la Monarquía era el anteriormente apuntado. El 10 de mayo de 1776 el conde de Aranda desde la embajada de París aconsejaba enviar a la zona un cuerpo de tropas, aunque fuera mediano porque era muy probable que los británicos no se decidiesen a sostener la pretensión lusa ante la gravedad de los acontecimientos en sus territorios americanos ${ }^{6}$.

Desde San Ildefonso el 5 de agosto de 1776 José de Gálvez comunicó al conde de Ricla que en el día anterior había remitido a Cevallos la instrucción reservada para el mando de la expedición que el Rey se había dignado confiarle. Le planteaba que debía tenerla presente para formar la del gobierno «de las provincias que el Rey se ha servido sujetar al mando y nuevo virreinato del mismo general Cevallos», por lo que debía pasarle la citada instrucción militar ${ }^{7}$. Se le especifica que esa expedición tenía dos objetos principales, el primero poner a cubierto Buenos Aires, Maldonado, Montevideo y demás fuertes del dominio español, y por otro «tomar la isla de Santa Catalina y la Colonia del Sacramento con la circunstancia de cegar su puerto». Si bien la conquista de la isla era el objetivo principal y preferente, se le dejaba a su arbitrio la elección «por primera operación la que os parezca más ventajosa y proporcionada según las noticias que adquiráis de los progresos de los enemigos y el estado en que halléis aquellas cosas» ${ }^{8}$.

\section{LA EXPEDICIÓN DE CEVALLOS}

La instrucción que dio pie a tal expedición especificaba que debían participar en ella ocho mil hombres de infantería, 600 dragones, 400 artilleros, un destacamento de obreros de maestranza y una brigada de diez ingenieros. Esta última demuestra el afán de control cartográfico y militar de la región limítrofe objeto de controversia. Su objeto era recuperar los puestos que habían tomado los portugueses en el Rio Grande de San Pedro, como también la conquista de cualquier otro, como la isla de Santa Catalina o la Colonia de Sacramento. El 13 de noviembre de 1776 salió de Cádiz una flota de 116 embarcaciones. Tras hacer una corta escala en Canarias, se dirigieron a la ocupación de la Isla de Santa Catalina. El tinerfeño Lope de la Guerra especificó en

\footnotetext{
${ }^{5}$ Archivo General de Simancas (A.G.S.) S.G.U. Leg. 6833, 1.

${ }^{6}$ Sanz Tapia, El final, 46.

7 A.G.S. S.G.U. Leg. 6833, 1.

8 A.G.S. S.G.U. Leg. 6833, 1.
} 
sus memorias como fue vista la expedición a los ojos de la opinión pública en su escala en Santa Cruz de Tenerife. Subrayó que

en 20 noviembre pasó por esta isla la Escuadra del mando del Teniente General Marques de Casatilly, que se componía de 116 embarcaciones que llevaban 40.000 hombres de desembarco al mando del Teniente General Don Pedro Cevallos, hijo del Intendente Don Juan Antonio de Cevallos, cuya desgraciada muerte hecha en el lugar de Santa Cruz año de 1720 será siempre sensible a los isleños. (...) Solo traían siete días de navegación y aun no sabían su destino. Infiérese que era hacia Buenos aires a expulsar los portugueses de algunos terrenos que habían usurpado por el Río de la Magdalena, por lo que corren voces de que se tiene casi declarada la guerra a los ingleses y portugueses?.

Tras el asalto de los fuertes de Santa Cruz y de la isla Ratones, marcharon hasta la capital para exigir su rendición el 26 de marzo de 1777. Fue conquistada sin la pérdida de un solo hombre por la poca resistencia local. A continuación, las tropas se dirigieron hacia la Colonia, que cayó también con relativa facilidad junto con la isla de San Gabriel. Al parecer el Marqués de Pombal consideraba prácticamente imposible su defensa, por lo que era necesario abandonarla. Casi simultáneamente a esa ocupación, Carlos III expidió el 11 de junio de 1777 una real cédula por la que se ordenó a Cevallos el cese de las hostilidades. Se dio paso a unas negociaciones entre los dos países que culminaron con la firma del Tratado de San Ildefonso de 1 de octubre de 1777, que delimitó de forma definitiva en la región las fronteras entre ambos países ${ }^{10}$. Esto último, sin embargo, en teoría, porque el proceso fue mucho más complejo. Designado para tal fin José de Varela y Ulloa, el proceso se eternizó ${ }^{11}$.

La expedición permaneció hasta junio de 1778 en Buenos Aires, hasta que se determinaron los efectivos necesarios para la defensa de la capital del Virreinato, poniendo rumbo en esa fecha los buques hacia la Península. Como señala Juan Marchena, a pesar de su envergadura, las fricciones entre la Real Armada y el Ejército de tierra fueron constantes, al recaer el mando marino en el marqués de Casa Tilly y el terrestre en Pedro de Cevallos ${ }^{12}$. Pero así estaba configurado en la etapa de gobierno de Indias de José de Gálvez, en el que en las unidades terrestres recaía por entero su mando en el malagueño, mientras que las marinas eran independientes y supeditadas

\footnotetext{
${ }^{9}$ Lope Antonio Guerra y Peña, Memorias. Tenerife en la segunda mitad del siglo XVIII, (Las Palmas: Ediciones del Cabildo Insular de Gran Canaria, 2002), 392-393.

${ }^{10}$ Julio Beverina, La expedición de Don Pedro de Cevallos en 1776-1777, (Buenos Aires: Editorial Rioplatense, 1977).

${ }^{11}$ María Soledad Lollo, "La partida demarcadora de Varela y Ulloa en el Río de la Plata. Propuesta borbónica y condicionamientos en la frontera hispano-portuguesa" en Boletín Americanista 74 (2017) 163180.

12 Juan Marchena Fernández, "Llevar la guerra al otro lado del mundo: Reforma e Ilustración en las guerras de España contra Portugal. La gran expedición militar al Brasil y al Río de la Plata en 1776" en El Estado en guerra. Expediciones navales españolas en el siglo XVIII, María Baudot Monroy, (Madrid: Ediciones Polifemo, 2014) 195-259.
} 
por entero al marqués de Castejón. La guerra de independencia de las Trece Colonias dejaría bien a las claras esas desavenencias ${ }^{13}$.

Francisco de Saavedra, en su diario personal, reflejó que la expedición de Cevallos fue

Una de las empresas mejor concertadas y provistas que se han hecho en España; así sus efectos fueron, aunque infructuosos, felices. Se conquistó la isla de Santa Catalina, posición excelente para escala de la mar del Sur; se tomó la isla (sic) del Sacramento, que era una madriguera de contrabandistas, y se arrojó a los portugueses de las cercanías del río Grande ${ }^{14}$.

El político sevillano precisa bien. Fue una expedición exitosa, pero sus efectos fueron negativos. En efecto, pese a la basa que representaba la posesión de Santa Catarina, la monarquía no supo mantenerla, alegando los costes que originaría su establecimiento en un medio hostil. Pero más grave aún el hecho de que no se intercambiase por un territorio ya ocupado por los lusos. A la muerte de José I, su hija y sucesora María I depuso a Pombal. Por el nuevo tratado Portugal recuperaría esa isla, Río Grande y los territorios del sur y España con la Colonia del Sacramento, la isla de San Miguel y las misiones orientales. Una nueva comisión de límites dictaminaría sobre las fronteras interiores de Paraguay, Moxos y Chiquitos, cuya dilucidación, como subrayamos, sería infructuosa en la práctica. Lo absurdo era que la compensación por la cesión de Santa Catarina eran las islas de Annobón y Fernando Póo en el golfo de Guinea, unos territorios que en realidad no habían sido ocupados por los lusos, por lo que se obligaba a los españoles a conquistarlos con la oposición de sus habitantes. Era un disparate a todas luces porque Portugal no cedía sus establecimientos de San Tomé y Puerto Príncipe, donde estaba asentado, o el archipiélago de Cabo Verde, sino unas islas de las que nunca había tomado posesión.

\section{LA EXPEDICIÓN DE CONQUISTA DE FERNANDO PÓO Y ANNOBÓN}

El objetivo de José de Gálvez con la intervención en las costas próximas de Guinea era doble. Por una parte favorecer la trata esclavista, y por otra contar con un punto de avituallamiento y de escala en la nueva ruta hacia Filipinas que trataba de desarrollar con la erección de una compañía monopolista con esa finalidad, todo ello integrado y dependiente del Virreinato del Río de la Plata. Así lo reflejó el mismo virrey Juan José de Vertiz en su memoria dirigida a su sucesor marqués de Loreto, fechada en Buenos Aires el 12 de marzo de 1784:

La de Annobón, situada en la costa de África en once grados treinta minutos sud distante del Cabo de Lope Gonzalo, en la costa de Guinea 44 leguas, tiene buen

\footnotetext{
${ }^{13}$ Manuel Hernández González, El Círculo de los Gálvez: Formación, apogeo y decadencia de una elite de poder indiana, (Madrid: Ediciones Polifemo, 2019).

${ }^{14}$ Francisco Saavedra, Los decenios (Autobiografía de un sevillano de la Ilustración). Transcripción, introd. y notas de Francisco Morales Padrón, (Sevilla: Excmo. Ayuntamiento de Sevilla, 1995) 103.
} 
fondeadero: la suponen de suelo fértil, y sano; y de proporción para hacer abundante en algodón, cañas dulces, maíz, y otros frutos. La de Fernando del Pó, en el golfo de Guinea en tres grados Norte de la línea, distante solo doce leguas de la costa, siguiendo luego la de Santo Tomé, y otras que se reservaron los Portugueses. Esta adquisición llevó por objeto hacer el comercio de negros, y tener alguna arribada propia en caso de necesidad al tiempo de montar, o de bajar el cabo de Buena Esperanza de ida o vuelta de Filipinas, y también poderse establecer los Españoles en ellas, y negociar en los puertos, y costas opuestas a otra Isla de Fernando del Pó como son los del rio Gabaón, de los Camarones, de Santo Domingo, Cabo Fermoso, y otros de aquel distrito, sin que por esto se impida hacer el mismo comercio a los vasallos de Portugal ${ }^{15}$.

Saavedra en su diario personal ya expresó con contundencia el fracaso de ese tratado, al aseverar que, al hallarse la reina de Portugal en San Ildefonso en conversaciones con su hermano el monarca español, en ella seguramente obraba el espíritu de Pombal. De tales resultas se dio pie a «una paz muy desventajosa, a que contribuyó no menos la condescendencia de Carlos III con su hermana, que la escasez de luces de nuestro gabinete». Sus reflexiones no dejaban lugar a dudas sobre ese desaguisado al devolver Santa Catalina,

que ofrece la mejor escala posible para el Perú; además se les dejó en posesión las márgenes del Río Grande, que tanto apetecían y les interesaba, y nos contentamos con retener la Colonia del Sacramento, bicoca despreciable situada en nuestro territorio, admitiendo en desquite de lo mucho que cedíamos las dos miserables islas en la costa de África llamadas Anobón y Fernando del Pó (sic), que ni tenían puerto, ni eran habitables, ni reconocían la dominación de Portugal ${ }^{16}$.

Fernando Póo nunca había sido ocupado por los portugueses, conservando sus pobladores, los bubis, su estructura étnica y su cultura y religión tradicionales, mientras que Annobón estaba ocupada por descendientes de antiguos esclavos lusos huidos del sistema de plantaciones, convertidos al catolicismo mezclado con prácticas animistas. Las dos tenían en común su rechazo a la colonización portuguesa por la esclavización que de ella derivaba.

Los tratados de San Ildefonso de 1777 y del Pardo, del año siguiente, que lo confirmaba y refrendaba, conducían a la Corona española a la ocupación de Annobón y Fernando Póo. Se daba paso de esa forma a una frustrada expedición de colonización en el Golfo de Guinea. Tres artículos secretos del de San Ildefonso, refundidos en dos en el del Pardo cedían la Corona española ambas islas, como si las dos hubiesen pertenecido Portugal. En uno de ellos se hacía expresa mención a la compra y venta de esclavos «sin ligarse contratas y asientos perjudiciales, como los que en otro tiempo se hicieron con las compañías portuguesa, francesa e inglesa, los cuales fue preciso

\footnotetext{
${ }^{15}$ Memorias de los virreyes del Río de la Plata, (Buenos Aires: Bajel, 1945), 95.

${ }^{16}$ Saavedra, Los decenios, 112.
} 
cortar o anular» ${ }^{17}$, precisa mención a que ahora los españoles se harían cargo por sí de la trata, como se materializaría en 1789 con su liberalización.

Había plena conciencia de sus objetivos. Por eso se quiso tranquilizar a las compañías negreras hasta el punto que el 16 de mayo de 1778 la monarquía requirió a sus embajadores de Londres y París que tranquilizasen a tales gobiernos al expresarse que si este tratado

debía servir para procurar a la América española los brazos que necesitaba, era tan grande la falta de aquellos que, indudablemente, seguirían adquiriéndose una buena cantidad de negros a sus proveedores habituales ${ }^{18}$.

Solo veinticuatro días después de la firma del Tratado de El Pardo, el 17 de abril de 1778, salió de Montevideo una expedición española mandada por el conde de Argelejo desde el punto de vista del ejército, con un segundo al teniente de artillería Joaquín Primo de Rivera, y desde el punto de vista de la marina el jefe de la flota era el capitán de fragata José de Varela y Ulloa, un mando bicéfalo, como ya vimos en la anterior incursión, con el objetivo de tomar posesión de esos nuevos territorios. El 29 de junio arribaron a la isla de Príncipe, pero el gobernador lusitano se negó a ceder su soberanía, por lo que hubieron de esperar tres meses hasta que desembarcase un comisario de ese país con órdenes de su Corte de otorgárselos. Este, que debía haber estado allí, solo arribó a ella el 4 octubre, tres meses después. Con ese retraso perdió por completo su carácter secreto al fondear en su rada buques negreros holandeses, ingleses, franceses y daneses ${ }^{19}$. Durante su estancia fueron muy mal tratados por las autoridades lusas. Los víveres les eran vendidos a precios abusivos y muchos de los expedicionarios murieron a consecuencia de las fiebres. Argelejo quiso marchar por su cuenta sin el comisario, pero Varela y Ulloa, alegando las instrucciones, se negó a proceder a ello. Este último debió temer un enfrentamiento directo por ello con los portugueses, en unas aguas dominadas por ellos y por los británicos. Era evidente también tanto la falta de suministros y víveres, como el desconocimiento del territorio.

El marino tenía claro que lo que debía hacer la Corte española era «pedir a los portugueses la Isla de Príncipe, en la cual hay una Regular Población, y un mediano puerto». A partir de esa posesión se podría construir una fortaleza en el Gabón, cuyo comercio era el que necesitaba España y posibilitar con ello la trata esclavista, incluso la clandestina, a la que se prestan tanto daneses como ingleses y holandeses ${ }^{20}$.

${ }^{17}$ Manuel Cencillo de Pineda, El brigadier conde de Argelejo y su expedición militar a Fernando Póo en 1778, (Madrid: Instituto de Estudios Africanos, 1948), 66-67.

${ }^{18}$ Reproducido por Juan Bautista Vilar en "España en Guinea Ecuatorial (1778-1892)” en Anales de la Universidad de Murcia, XXVIII, 3-4 (1969-70), 265-306, 269.

${ }^{19}$ María Dolores García Cantús, Fernando Póo. Una aventura colonial española en el África occidental 1778 1900. Tesis doctoral. (Valencia: 2002-2003), 49.

${ }^{20}$ Opiniones de su manuscrito Descripción de la isla de Annobón, reproducidos en García Cantús, Fernando Póo, 53. 
Con la arribada del comisario portugués el 14 de octubre de 1778 pudieron salir de la isla de Santo Tomé los militares españoles. Siete días después desembarcaron en la de Fernando Póo, donde al tercer día tomaron posesión de ella. La situación era tan absurda que el comisionado luso le proporcionó el acta de posesión, mientras que sus habitantes huían al mismo tiempo hacia el interior de la isla. En ese instante Argelejo

lanzó tierra al aire y quebró ramas de los árboles e hizo todos los demás actos posesorios diciendo en altas voces, de modo que todos los presentes lo entendieron, que en virtud de la comisión que tenía del Rey Católico(...) tomaba posesión de esta isla de Fernando Póo como perteneciente al Reino de España para que de hoy en adelante reconocieran sus habitantes a dicho Soberano como su Rey con pleno y supremo poder ${ }^{21}$.

La erección de una fortaleza en esa área de la isla que habían denominado bahía de San Carlos era sumamente costosa y además no disponían de medios y materiales para ejecutarla. El 25 de octubre marcharon hacia la de Annobón, de la que no pudieron controlar por la actitud levantisca de sus naturales, que no se aceptaban ni la soberanía lusa ni la española, ante lo que el comisario portugués se contentó con manifestar que su país había cumplido. En la travesía murió el jefe de la expedición, por lo que le sustituyó su segundo, Joaquín Primo de Rivera. Para hacer frente a la rebelión de los nativos el lusitano José de Soussa al frente de dos fragatas salió de Lisboa con la finalidad de poner fin al levantamiento.

Ante la plasmación de esa evidente realidad, se trasladó por Argelejo un informe en el que reconocía que no se trataba de traspasar la soberanía, sino de una empresa de auténtica conquista, por lo que en ese caso era mejor la de Fernando Póo

por cuanto se extrañan sólo por falta de cultivo, y no haber conocido civilidad jamás, ni unión republicana, que a los de Annobón, que, habiéndola tenido, y reconocido, están hechos a sacudirla y extrañarse por elección ${ }^{22}$

Varela, por su parte, plantea las ventajas de Fernando Póo para el comercio, pero también las dificultades por ser «muy difícil reducir y civilizar aquellos isleños acostumbrados a vivir en los montes; y que tal vez no gustaran de sujetarse a las leyes que quieren imponerles unos europeos, cuya bandera nunca han visto en sus orillas» ${ }^{23}$. Rechazaba Annobón por su carácter improductivo y la resistencia de sus habitantes a los portugueses.

Ante la rotundidad de esos informes Floridablanca comunicó el 16 de marzo al embajador portugués en España una nota en la que afirmaba que «en fuerza de lo acaecido se encontraba el Rey en derecho de exigir, con arreglo a la buena fe, se le

\footnotetext{
${ }^{21}$ Reprod. en Cencillo de Pineda, El brigadier, 102.

22 Reprod. en García Cantús, Fernando Póo, 57.

${ }^{23}$ Reprod. en Ibídem., 59.
} 
ponga en pacífica posesión de dichas islas, o se le dé por la Reina Fidelísima un equivalente de ellas» ${ }^{24}$.

\section{EL INTENTO DE COLONIZACIÓN DE FERNANDO PÓO}

El 29 de noviembre de 1779 se procedió a instalar en la bahía de la Concepción en Fernando Póo el nuevo establecimiento. Pero para que la nueva población se desarrollase era necesaria la conducción de soldados con sus familias, de forma similar a lo que por aquellas mismas fechas la Corona estaba procediendo a hacer en Luisiana. El transporte de familias canarias había sido desde la real cédula de 1676 el recurso habitual de la Monarquía para colonizar y erigir nuevos pueblos en las colonias americanas, por lo que se dio curso a los nuevos planteamientos en tierras africanas. El 21 de noviembre de 1779 la fragata Santiago, comandada por el sargento mayor el lagunero Antonio José Eduardo salió de Santa Cruz de Tenerife con 104 hombres entre soldados, operarios y familiares.

Para proceder al transporte, como había acontecido por esas mismas fechas con Luisiana, se ofrecieron muchos navieros, cuyos barcos estaban desocupados por la crisis del tráfico canario-americano y por la guerra. De esa forma, desde Santa Cruz de La Palma Antonio Viña, capitán y dueño de La Paloma isleña, «por cuanto por el Juez superintendente de Indias se dirigió carta al subdelegado en esta, comunicándole una superior orden con que se hallaba para fletar un navío de los mayores de esta carrera a fin de transportar víveres» para tales islas, dio poderes al comerciante Dionisio O’Daly para que gestionase su oferta ${ }^{25}$. Sin embargo, se prefirió la menos onerosa del lagunero Antonio Eduardo, su capitán y director, que fallecería en Santo Tomé. Su barco «El Santiago», al mando del capitán francés Sicart, que en realidad era su segundo piloto, pero se vio obligado a actuar como tal tras la muerte de Eduardo y del primero Jerónimo Guía, acaecida en alta mar, arribaría el 19 de septiembre a Fernando Póo procedente de Santo Tomé. El buque estaba ya en mal estado al salir de Canarias, por lo que quizás por ello su armador lo donó a la Real Hacienda sin más obligación que el coste del seguro. A su llegada, según declaración del mismo Sicart

tenía toda la proa podrida así por dentro como por de afuera, se halla el palo de trinquete asimismo podrido, igualmente su verga de bauprés y timón rendido, los trancaniles abiertos que no son suficientes a impedir se introduzca el agua a chorros en la bodega asimismo se halla el palo mayor rendido por bajo..., y ya tenemos representado el exterminio en que se hallan los cables. Este navío, según se experimentó en la mar, hace más agua por la parte de estribor, llevando la mura a babor, pues hacía seis pulgadas por hora, por ser un barco tan viejo, y que tiene treinta

\footnotetext{
${ }^{24}$ Reprod. en Cencillo de Pineda, El brigadier, 112.

25 Archivo Histórico de la Palma (A.H.L.P.) Protocolos notariales n ${ }^{\circ} 586$. Francisco Mariano López de Abreu (1779). Poder desde Santa Cruz de La Palma, 28 de junio de 1779.
} 
y cuatro años asimismo sus cables, jarcias, y demás maniobras se hallan en grande exterminio ${ }^{26}$.

El establecimiento no prosperó por las enfermedades y las fiebres que diezmaron a los expedicionarios, que no contaban con quina, siendo los socorros pedidos a Santo Tomé escasos y tardíos. Hasta el 27 de junio de 1780 fallecieron 83 miembros de la expedición, en los que se incluían los militares llegados con anterioridad. Se hallaban 57 personas hospitalizadas, teniendo que tomar los enfermos a falta de otra cosa mejor, caldo de mono, por lo que en julio de 1780 partió para Santo Tomé el Santiago para su reparación con 27 soldados, tres oficiales y varios operarios, todos ellos indispuestos. Los disgustos de los habitantes de esa población derivaron en el amotinamiento de los supervivientes, que arrestaron al jefe de la expedición, Primo de Rivera. el levantamiento liderado el 24 de septiembre d 1780 por el sargento $1^{\circ}$ de infantería Jerónimo Martin contra el teniente coronel Primo de Rivera, quien fue arrestado y encarcelado por los amotinados. Las razones expuestas por los insurrectos para proceder a ello se debían a la gravedad de la situación, la escasez y mal estado de los víveres, la multitud de enfermos y el deseo de abandonar la isla.

El virrey Vertiz expuso que

la Isla se abandonó con toda la artillería, útiles y obras construidas en aquel establecimiento, las que por posteriores noticias se sabe fueron arruinadas y entregadas al fuego por aquellos naturales, que nunca quisieron tratar con los nuestros, conservándose retirados y escondidos en los bosques y malezas de que está circundado la Isla siendo impenetrable a hombres y animales desde la misma orilla del agua ${ }^{27}$.

Por todo ello, se decidió la marcha de Concepción el 30 de octubre de 1780 con rumbo a Santo Tomé, donde fueron apresados y en la que fue puesto en libertad Primo de Rivera. Debido al gran número de bajas habidas se optó finalmente por abandonar la factoría y dirigirse a América. El 24 de febrero de 1782 arribaron a Salvador de Bahía, en la que por espacio de más de diez meses estuvieron reparando las naves. Se arribó a Montevideo el 10 de febrero de 1783. Los amotinados fueron entregados al Virrey de Buenos Aires. Por la real orden de 25 de mayo de 1785 se indultó a su cabecilla el sargento Jerónimo Martín, por el gran número de bajas habidas. Los resultados de este proyecto colonizador fueron desastrosos ya que se abandonó el establecimiento de la Concepción y no se pudo hacer efectiva la soberanía ni en esa isla ni en ningún punto del continente. En cuanto a Annobón ni siquiera se llegó a tomar posesión por los incidentes experimentados con sus naturales.

Se conserva una relación de todos esos acontecimientos debida a la pluma del capellán del Santiago, el franciscano lagunero Manuel González Ramos, cuya presencia

\footnotetext{
${ }^{26}$ Reprod. en Luis Fernando Furlán, "Notas sobre la expedición del conde de Argelejo y la presencia española al Golfo de Guinea (1778-1783)", en VI Simposio de Historia maritima y naval iberoamericana, (Lima), 1-29, 21.

${ }_{27}$ Memorias de los virreyes, 97-98.
} 
se entendía para dar el pasto espiritual a los colonos y evangelizar a los indígenas ${ }^{28}$. En ella especificó que salieron de Tenerife el 21 de noviembre de 1779 a raíz de una real disposición ordenada al juez de indias Bartolomé de Casabuena. Sin embargo, se ignoraba si ya se había tomado posesión de ella, por lo que su inmediato objeto era la localización del comandante de la expedición. Arribaron a Santo Tomé el 4 de marzo de 1780, donde se le dio noticia de la ocupación de Fernando Póo y de la resistencia de los nativos en la de Annobón. Desembarcaron en la primera el 14 de abril, donde hallaron "así el campamento como la marina apestados del escorbuto y otras enfermedades que allí se padecían, las que, acompañadas de adversidades y destituidas de auxilios, fueron de día en día creciendo las mayores penalidades y miserias de la más desgraciada expedición», hasta el punto de que «El Santiago de Tenerife» fue la única fragata que quedó sana en la isla «para recoger los tristes residuos» que quedaron de ese establecimiento.

Los estragos de las enfermedades se acrecentaron en el mes de agosto de 1780 hasta el punto de que «llenaba de terror y espanto a los sanos, concurriendo a abatir los ánimos de los afligidos enfermos la escasez de dietas, falta de médico y comodidad del hospital». Aconteció después de la citada rebelión, mientras que se dilataba la llegada de refuerzos que solo acaeció con la llegada el 23 de septiembre de la fragata portuguesa «nuestra Señora del Carmen, que condujo desde Canarias dos oficiales, un capellán, un sargento y 20 hombres de tropa, entre reclutas y viejos, cuando no quedaba dinero para subsistir». Incluso sufrieron la incursión de una fragata inglesa contra «el Santiago de Tenerife» el 23 de septiembre de 1781, frente a la que «los canarios, aunque sin fuerzas, cargados de achaques epidémicos, tuvieron valor para defenderse con honor». Los británicos rompieron el fuego al abordaje por la proa de la nao. Los isleños le respondieron de tal suerte que «se numeraron de los ingleses 27 muertos y dos que aparecieron tendidos sobre cubierta por haberse entrado y cuatro que fueron mal heridos» por lo que se computaron 33 los fallecidos. Por parte de los canarios, solo hubo tres heridos, de los que uno, el natural de Las Palmas Francisco Gil murió a los quince días por haber sido grave la herida en una ingle. Otro de los contusionados, el santacrucero José Martín de Saá, murió más tarde en Brasil, aunque sin ser a consecuencia de tales daños.

De los 104 expedicionarios canarios de la fragata Santiago, incluidos entre ellos el capitán y el capellán, habían muerto 56 y quedaban vivos 46. Ante tan catastrófica situación "para evitar el sacrificio de los tristes residuos», se puso fin a esa desastrosa primera experiencia colonizadora española en Guinea Ecuatorial y se resolvió retirarse hacia el Río de la Plata por ser el paraje más a propósito para conducir la expedición sin riesgo de ataques enemigos y esperar en él nuevas disposiciones regias. Salieron de Santo Tomé el 29 de diciembre de 1781 y arribaron a Salvador de Bahía el 24 de febrero de 1782. Se vieron obligados a carenar el navío por su grave estado, viéndose obligados a permanecer en ese puerto hasta el 10 de febrero de 1783 por la presencia en sus aguas de catorce navíos británicos armado. Finalmente pudieron desembarcar en

\footnotetext{
${ }^{28}$ Manuel González Ramos, Relación de viaje a Guinea del navio El Santiago. Manuscrito. Museo Canario. Fondo Gregorio Chil y Naranjo, 1490.
} 
Montevideo el 10 de febrero de 1783, siendo sorprendidos a su entrada por una gran tormenta en el río. Allí permanecieron hasta que por una orden real se les ordenó la navegación hacia España el 28 de mayo de 1784. Tras desembarcar en Cádiz el 19 de septiembre de ese año, marcharon a Tenerife a entregar la fragata a su dueño. El fin de tan larga travesía acaeció el 2 de marzo de 1785. Finaliza su exposición fray Manuel González Ramos expresando que «El Santiago de Tenerife, que se había librado, no sin milagro de tantas borrascas, vino a perecer, entregada a sus amos, al entrar por la barra de Lanzarote, cuando fue desde Tenerife a carenarse $\rangle^{29}$.

Después de tan desastrosa expedición, José de Gálvez persistió en sus intenciones de colonizar esas dos islas para convertirlas en lugares de escala de la Compañía de Filipinas. En su calidad de presidente de ella, en la sesión de su junta de gobierno de 11 de diciembre de 1783 esa empresa asumió la necesidad de erigir una colonia mercantil en la Guinea. En sucesivas reuniones se trató de acometerla por cuenta del gobierno con el encargo de su administración. Antonio Ricardos y Gaspar Leal se ocuparon de formular el 15 de diciembre de 1786 una propuesta al respecto. Pero todo quedó en saco roto con la muerte del marqués de Sonora al año siguiente ${ }^{30}$. La colonización de la Guinea Ecuatorial por España tardaría en verificarse ochenta años después. Concluiría de esa forma una empresa colonizadora que demostró a las claras el profundo desconocimiento que tenían las autoridades españolas de la realidad de la región, lo que explica que sucumbieran ante las propuestas conscientemente irreales de los lusos, que recuperaron Santa Catarina con la concesión a la Corona hispana de unas posesiones a todas luces imaginarias, lo que derivó en su frustrada colonización, sin contar con los medios ni con los recursos humanos para llevarla a cabo contando además con la frontal oposición a ella de sus habitantes.

\footnotetext{
${ }^{29}$ Ibídem.

${ }^{30}$ Cencillo de Pineda, El brigadier, 174-175.
} 


\section{BIBLIOGRAFÍA}

Barba, Enrique M., Don Pedro de Cevallos, (Madrid: Ediciones de Cultura Hispánica, 1988, $3^{\text {a }}$ ed.).

Beverina, Julio, La expedición de Don Pedro de Cevallos en 1776-1777, (Buenos Aires: Editorial Rioplatense, 1977).

Cencillo de Pineda, Manuel, El brigadier conde de Argelejo y su expedición militar a Fernando Póo en 1778, (Madrid: Instituto de Estudios Africanos, 1948).

Din, Gilbert, Los canarios de Luisiana, (Las Palmas: Casa de Colón, 2010).

Furlán, Luis Fernando, "Notas sobre la expedición del conde de Argelejo y la presencia española al Golfo de Guinea (1778-1783)", en VI Simposio de Historia marítima y naval iberoamericana, (Lima), 1-29.

Hernández González, Manuel, "Bajo el impulso regio. La migración canaria y los batallones de Cuba y Luisiana (1776-1798)", en Del espacio cantábrico al mundo americano: perspectivas sobre migración, etnicidad y retorno, coord. Álvarez Gila, Óscar, Amores Carredano, Juan Bosco, (Vitoria: Universidad del País Vasco, 2015), 141-169.

Hernández González, Manuel, El Círculo de los Gálvez. Formación, apogeo y decadencia de una elite de poder indiana, (Madrid: Ediciones Polifemo, 2019).

Hernández González, Manuel, Una rebelión contra la Intendencia. El motín de Santa Cruz de Tenerife de 1720, (Tenerife: Ediciones Idea, 2007).

García Cantús, María Dolores, Fernando Póo. Una aventura colonial española en el Africa occidental 1778-1900, (Tesis doctoral, Valencia: 2002-2003).

González, Ramos, Manuel, Relación de viaje a Guinea del navio El Santiago, Manuscrito. Museo Canario. Fondo Gregorio Chil y Naranjo, 1490.

Guerra y Peña, Lope Antonio, Memorias. Tenerife en la segunda mitad del siglo XVIII, (Las Palmas: Ediciones del Cabildo Insular de Gran Canaria, 2002).

Lollo, María Soledad, "La partida demarcadora de Varela y Ulloa en el Río de la Plata. Propuesta borbónica y condicionamientos en la frontera hispano-portuguesa", Boletin Americanista 74 (2017): 163-180.

Marchena Fernández, Juan, "Llevar la guerra al otro lado del mundo: Reforma e Ilustración en las guerras de España contra Portugal. La gran expedición militar 
al Brasil y al Río de la Plata en 1776", en El Estado en guerra. Expediciones navales españolas en el siglo XVIII, Baudot Monroy, María, (Madrid: Ediciones Polifemo, 2014), 195-259.

Martínez de Salinas Alonso, María Luisa, La colonización de la costa centroamericana de la Mosquitia en el siglo XVIII. Familias canarias en el proyecto poblador, (Valladolid: Universidad de Valladolid, 2015).

Ramos, Demetrio, El Tratado de límites de 1750 y la expedición de Iturriaga al Orinoco, (Madrid: C.S.I.C., 1946).

Memorias de los virreyes del Río de la Plata, (Buenos Aires: Bajel, 1945).

Saavedra, Francisco, Los decenios (Autobiografía de un sevillano de la Ilustración. Transcripción, introd. y notas de Francisco Morales Padrón, (Sevilla: Excmo. Ayuntamiento de Sevilla, 1995).

Sanz Tapia, Ángel, El final del Tratado de Tordesillas: la expedición del virrey Cevallos al Río de la Plata, (Valladolid: Junta de Castilla y León, 1994).

Unzueta, Abelardo, Historia geográfica de la isla de Fernando Póo, (Madrid: Instituto de Estudios Africanos, 1947).

Vilar, Juan Bautista, "España en Guinea Ecuatorial (1778-1892)” en Anales de la Universidad de Murcia, XXVIII, 3-4 (1969-70), 265-306.

Recibido: 12 de julio de 2019 Aprobado: 23 de octubre de 2019 